\title{
The Structure and Stability of Molybdenum Ditelluride Thin Films
}

\author{
Zhouling Wang, Wenwu Wang, Ya Yang, Wei Li, Lianghuan Feng, Jingquan Zhang, \\ Lili Wu, and Guanggen Zeng
}

College of Materials Science and Engineering, Sichuan University, Chengdu 610064, China

Correspondence should be addressed to Wenwu Wang; www1492@163.com and Wei Li; waylee2000@sohu.com

Received 20 February 2014; Revised 23 May 2014; Accepted 26 May 2014; Published 10 July 2014

Academic Editor: Sudhakar Shet

Copyright (c) 2014 Zhouling Wang et al. This is an open access article distributed under the Creative Commons Attribution License, which permits unrestricted use, distribution, and reproduction in any medium, provided the original work is properly cited.

Molybdenum-tellurium alloy thin films were fabricated by electron beam evaporation and the films were annealed in different conditions in $\mathrm{N}_{2}$ ambient. The hexagonal molybdenum ditelluride thin films with well crystallization annealed at $470^{\circ} \mathrm{C}$ or higher were obtained by solid state reactions. Thermal stability measurements indicate the formation of $\mathrm{MoTe}_{2}$ took place at about $350^{\circ} \mathrm{C}$, and a subtle weight-loss was in the range between $30^{\circ} \mathrm{C}$ and $500^{\circ} \mathrm{C}$. The evolution of the chemistry for Mo-Te thin films was performed to investigate the growth of the $\mathrm{MoTe}_{2}$ thin films free of any secondary phase. And the effect of other postdeposition treatments on the film characteristics was also investigated.

\section{Introduction}

Molybdenum ditelluride $\left(\mathrm{MoTe}_{2}\right)$ belongs to the large family of layered transition metal dichalcogenides, which is bound by weak van der Waals interactions along the $c$-axis [1]. The electronic, optical, magnetic, and catalytic properties of the transition metal dichalcogenides have been extensively studied [2-6]. $\mathrm{MoTe}_{2}$ can act as an efficient absorbing layer in solar cells only if the crystallites of the films are textured with the $c$-axis perpendicular to the plane of the substrate [7]. Because of the layered structure of $\mathrm{MoTe}_{2}$, various metal atoms can be doped between the layers to change its optical and electrical properties [8]. It has been found that $\mathrm{H}$ absorption on $\mathrm{MoTe}_{2}$ monolayers results in large spatial extensions of spin density and weak AFM coupling between local magnetic moments even at the distance of above $12.74 \AA$ [4]. $\mathrm{MoTe}_{2}$ has a bandgap of around $1.1 \mathrm{eV}$ and a high work function of $\sim 4.7 \mathrm{eV}$, and the valence band offset of $\mathrm{CdTe} / \mathrm{MoTe}_{2}$ is only $0.03 \mathrm{eV}$ [1]; these are advantageous to the hole transport between cadmium telluride and molybdenum ditelluride. Therefore, $\mathrm{MoTe}_{2}$ is a potential candidate for a stable $\mathrm{Cu}$-free back contact to $\mathrm{CdS} / \mathrm{CdTe}$ solar cells.

Tellurium pressure or vapor is often indispensable for the preparation of the $\mathrm{MoTe}_{2}$ thin films $[9,10]$, and the adhesion or reproducibility of the films is very poor. In this work,
$\mathrm{MoTe}_{2}$ thin films were synthesized by solid state reactions between Mo and Te thin films followed by an anneal in $\mathrm{N}_{2}$ ambient. The structural property and stability of Mo-Te thin films were investigated under different postdeposition treatment conditions.

\section{Experimental}

Molybdenum-tellurium alloy thin films were deposited by electron beam evaporation at room temperature in the pressure of $\sim 10^{-4} \mathrm{~Pa}$. The multilayer Mo/Te films with a stacking sequence Te-Mo-Te-Mo were deposited independently and alternately using high purity molybdenum (99.999\% purity, Alfa Aesar) and tellurium (99.999\% purity, Alfa Aesar). The deposition rates of molybdenum and tellurium were monitored by a thickness monitor. The total thickness of the molybdenum-tellurium multilayer thin films was 200 $450 \mathrm{~nm}$. After deposition, a posttreatment was performed at different temperatures in $\mathrm{N}_{2}$ ambient. The temperatures reproducible to $\pm 1 \mathrm{~K}$ were obtained from repeated runs on the same sample.

The structure and the surface morphology of the samples were done by X-ray diffraction (XRD) (DX-2600, Dandong, China) and atomic force microscope (AFM) (MFP-3D-BIO, 


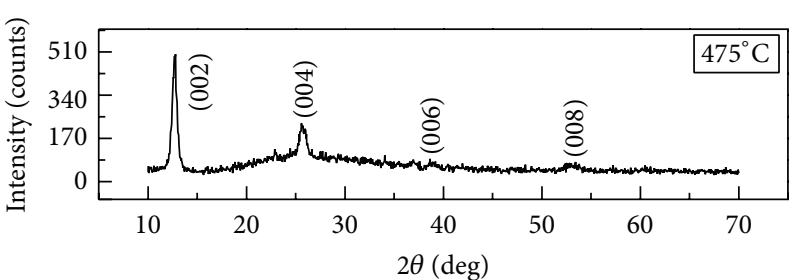

(a)

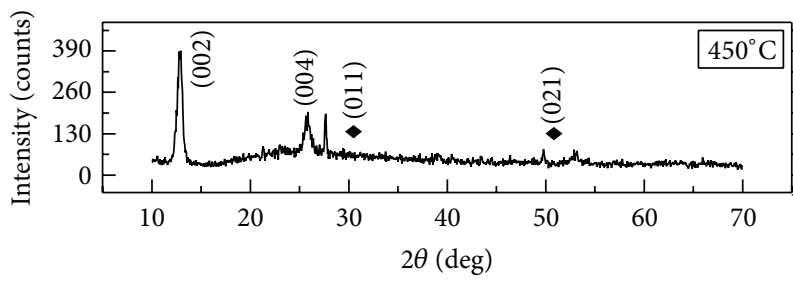

(c)

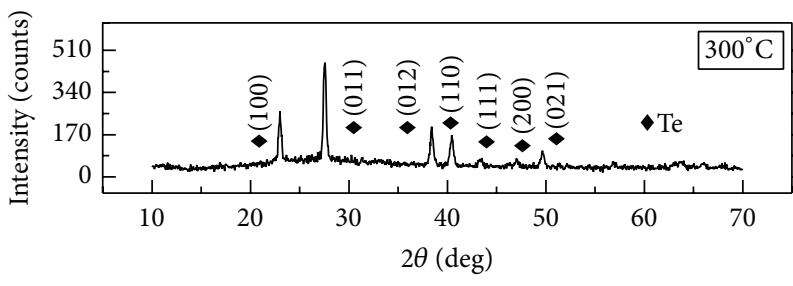

(e)

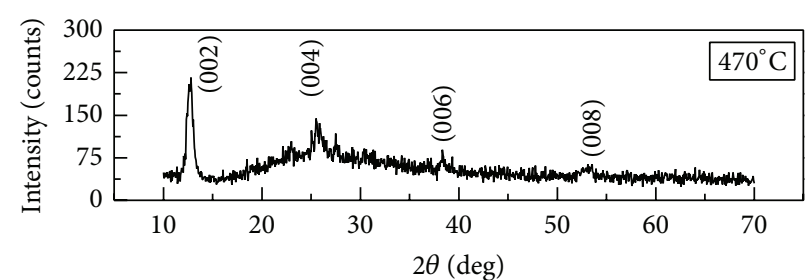

(b)

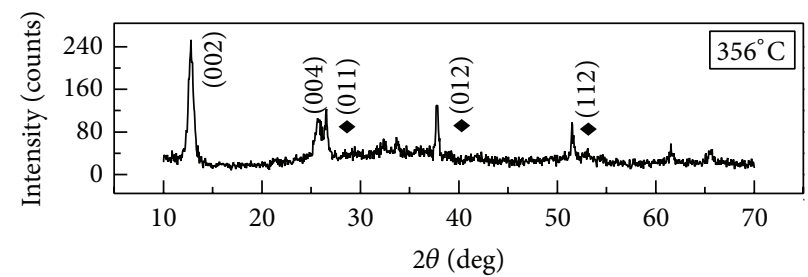

(d)

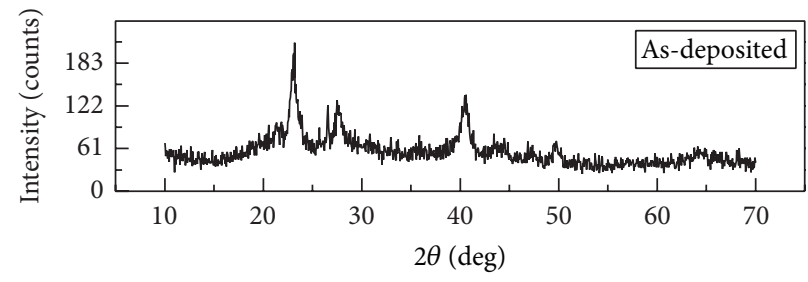

(f)

FIGURE 1: XRD patterns of Mo-Te thin films annealed at different temperatures for 15 min in $\mathrm{N}_{2}$ ambient.

Asylum Research, USA). The film thickness was surveyed using a stylus profiler (XP-2, Ambios Technology Inc., USA). To study the effect of annealing on the $\mathrm{MoTe}_{2}$ thin films, thermogravimetry and differential scanning calorimetry (TG/DSC) (STA 449C, NETZSCH, Germany) analysis were carried out. X-ray photoelectron spectra (XPS) (ESCALAB 250, Thermo Fisher SCIENTIFIC, UK) were performed to determine the atom chemical states.

\section{Results and Discussion}

Figure 1 shows the XRD patterns of the Mo-Te thin films with $450 \mathrm{~nm}$ thickness annealed at different temperatures in $\mathrm{N}_{2}$ ambient. The peaks marked by rhombus were indexed to the phase of Te (JCPDS NO. 65-3370), and the others were the phase of $\mathrm{MoTe}_{2}$ (JCPDS number 15-0658) (see Figure 1). The reflection positions in the XRD patterns of as-deposited layers were at the angles of $23.029^{\circ}, 27.560^{\circ}$, $40.454^{\circ}$, and $49.650^{\circ}$, which correspond to Te (100), (011), (110), and (021). In order to form the crystalline compound $\mathrm{MoTe}_{2}$ thin films with a simple hexagonal Bravais lattice, thermal postdeposition treatment was performed. The asdeposited thin films were annealed at $300^{\circ} \mathrm{C}, 356^{\circ} \mathrm{C}, 450^{\circ} \mathrm{C}$, $470^{\circ} \mathrm{C}$, and $475^{\circ} \mathrm{C}$ in $\mathrm{N}_{2}$ ambient, respectively. After annealing at $300^{\circ} \mathrm{C}$ in $\mathrm{N}_{2}$ ambient, many more diffraction peaks of Te, such as (012), (111), and (200), emerged at $38.263^{\circ}, 43.353^{\circ}$, and $47.060^{\circ}$. When the annealing temperature reached $356^{\circ} \mathrm{C}$, the patterns of the films were very different from those of the films annealed at $300^{\circ} \mathrm{C}$; the peaks corresponding to $\mathrm{MoTe}_{2}$ (002) and (004) were revealed by XRD patterns as shown in Figure 1. It was noticed that two diffraction peaks of $\mathrm{Te}$ (011) and (112) were also observed in the XRD patterns. The results show that a considerable amount of Te and Mo diffuses into the Mo and the Te films, respectively. The chemical reaction that took place in the thin elemental layers can be described as $2 \mathrm{Te}+\mathrm{Mo} \rightarrow \mathrm{MoTe}_{2}$. The thin films with well crystallization were achieved when annealing was performed at $470^{\circ} \mathrm{C}$ or higher. The peaks of $\mathrm{MoTe}_{2}$ (006) could be observed at $38.905^{\circ}$, and there were no peaks of Te. These results indicate the disappearance of Te but the presence of $\mathrm{MoTe}_{2}$ with increasing the annealing temperature. Therefore, annealing promotes the formation of $\mathrm{MoTe}_{2}$ and annealing at $470^{\circ} \mathrm{C}$ leads to the single phase $\mathrm{MoTe}_{2}$ thin films.

To study the stability of the molybdenum-tellurium alloy thin films, TG and DSC analysis were performed. The thin films as-deposited were cleaved from the substrates; approximately $2.952 \mathrm{mg}$ of sample was used in this work. The gas rate was $30 \mathrm{~mL} / \mathrm{min}$, and the heating rate was $10 \mathrm{~K} / \mathrm{min}$. Figure 2 shows the TG-DSC curves of as-deposited films. The peaks of as-deposited $\mathrm{MoTe}_{2}$ thin films were extended from $30^{\circ} \mathrm{C}$ to $600^{\circ} \mathrm{C}$. The peaks in DSC values meant endothermic reactions happened while heating. The first endothermic peak was located at $68.5^{\circ} \mathrm{C}$ and it was the endothermic peak of water. Then with the increase of temperature, there were endothermic peaks appearing at about $350^{\circ} \mathrm{C}$ and $448.5^{\circ} \mathrm{C}$ due to the energy consumption, which results from $\mathrm{Te}$ atoms and Mo atoms moving into lattice sites so as to form 


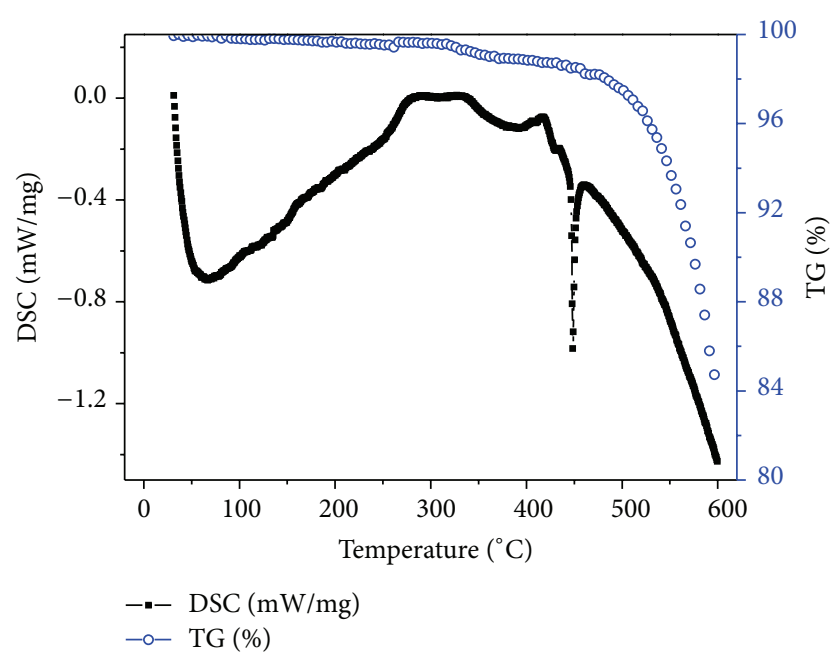

FIGURE 2: TG and DSC analysis of the as-deposited films.

$\mathrm{MoTe}_{2}$. This behavior is consistent with the results of XRD (Figure 1); that is, polycrystalline $\mathrm{MoTe}_{2}$ was gradually formed when the annealing temperature increased up to $350^{\circ} \mathrm{C}$. From the TG values also shown in Figure 2, one can see that there was almost no weight loss at the temperatures lower than $500^{\circ} \mathrm{C}$, whereas the TG curve dropped sharply at the temperatures higher than $500^{\circ} \mathrm{C}$. The severe weight-loss might be the reevaporation of tellurium for $\mathrm{MoTe}_{2}$, the results of which will be discussed later.

With the increase of the annealing temperature, the intensities of the peaks for the thin films became significantly strong and the positions of the peaks were not changed (Figure 3). These indicate the improved crystallinity and stable structure of $\mathrm{MoTe}_{2}$ thin films due to the interdiffusion. As the annealing temperature increased up to $500^{\circ} \mathrm{C}$, although the weight-loss was about $2 \%$ (Figure 2), an amorphous baseline distinctly appeared. We attribute the poor crystallinity of the films to the severe reevaporation of tellurium in the process of the postdeposition treatments. When the annealing temperature was further increased, the adhesion of the films was poor. Grain growth of $\mathrm{MoTe}_{2}$ thin films may introduce stress at the glass $/ \mathrm{MoTe}_{2}$ interface, resulting in film blistering or peeling.

Based upon the investigations of XRD and TG/DSC analysis, the evolution of the morphology and chemistry for $\mathrm{MoTe}_{2}$ thin films annealed at temperatures lower than $500^{\circ} \mathrm{C}$ was studied by AFM and XPS (Figures 4-5). Figure 4 shows the atomic force microscopy of Mo-Te thin films asdeposited and annealed at $475^{\circ} \mathrm{C}$ in $\mathrm{N}_{2}$ ambient. The surface of the as-deposited $\mathrm{MoTe}_{2}$ thin film was smoother than the one annealed at $475^{\circ} \mathrm{C}$. The root mean square of the asdeposited film was $1.179 \mathrm{~nm}$ while it became $19.803 \mathrm{~nm}$ after annealing. That means annealing could promote the growth of the grains. The well-distributed atoms moved to lattice sites so the valleys and peaks on the surface were detected by AFM, and this is consistent with the XRD results.

Figure 5 shows XPS spectra of Mo-Te thin films at different temperatures. When the annealing temperature was

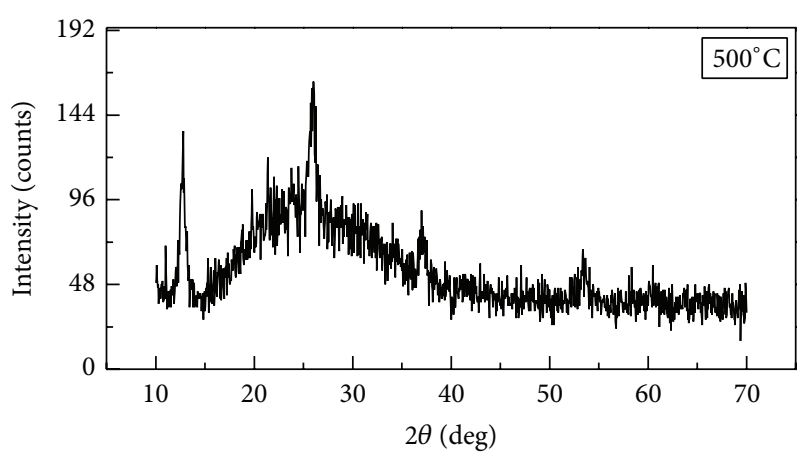

(a)

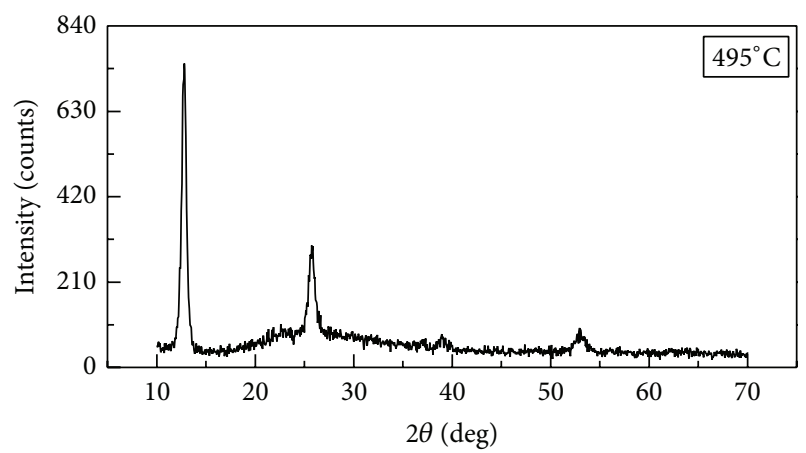

(b)

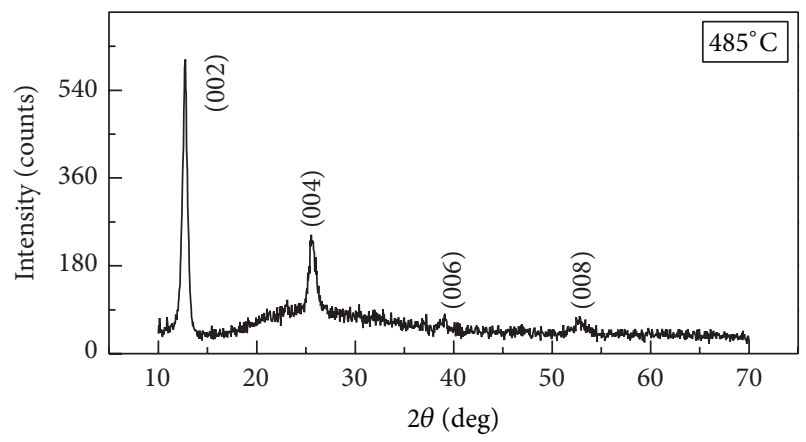

(c)

FIGURE 3: XRD patterns of Mo-Te thin films with a thickness of $450 \mathrm{~nm}$ annealed at $485^{\circ} \mathrm{C}, 495^{\circ} \mathrm{C}$, and $500^{\circ} \mathrm{C}$ for 15 minutes in $\mathrm{N}_{2}$ ambient.

below $450^{\circ} \mathrm{C}$, it was noticed that there was only one emission peak in XPS spectra of Mo $3 \mathrm{~d}_{3 / 2}$, which drew core level lines at about $232.75 \mathrm{eV}$, and it was a double peak. The emission peak with lower binding energies was determined to be the Mo $3 \mathrm{~d}_{5 / 2}$ in $\mathrm{MoTe}_{2}$ which occurred at $229.2 \mathrm{eV}$ when the annealing temperature reached $450^{\circ} \mathrm{C}$ or higher. That means $\mathrm{MoTe}_{2}$ was formed when the annealing temperature rose to $450^{\circ} \mathrm{C}$ and it has been confirmed by XRD in Figure 1. In Figure 5, the doublet of Te $3 \mathrm{~d}$ was doubled (the two Te $3 \mathrm{~d}_{5 / 2}$ peaks being at about $572.9 \mathrm{eV}$ and $576.5 \mathrm{eV}$ ), while the Te $3 \mathrm{~d}_{5 / 2}$ position of $\mathrm{TeO}_{2}$ occurred at $576 \mathrm{eV}$; maybe there was a small amount of tellurium oxidation at the surface of the films. It was obvious that the ratio of ionized Te/elemental Te increased dramatically after annealing since the peak area was proportional to the chemical composition. The results show 


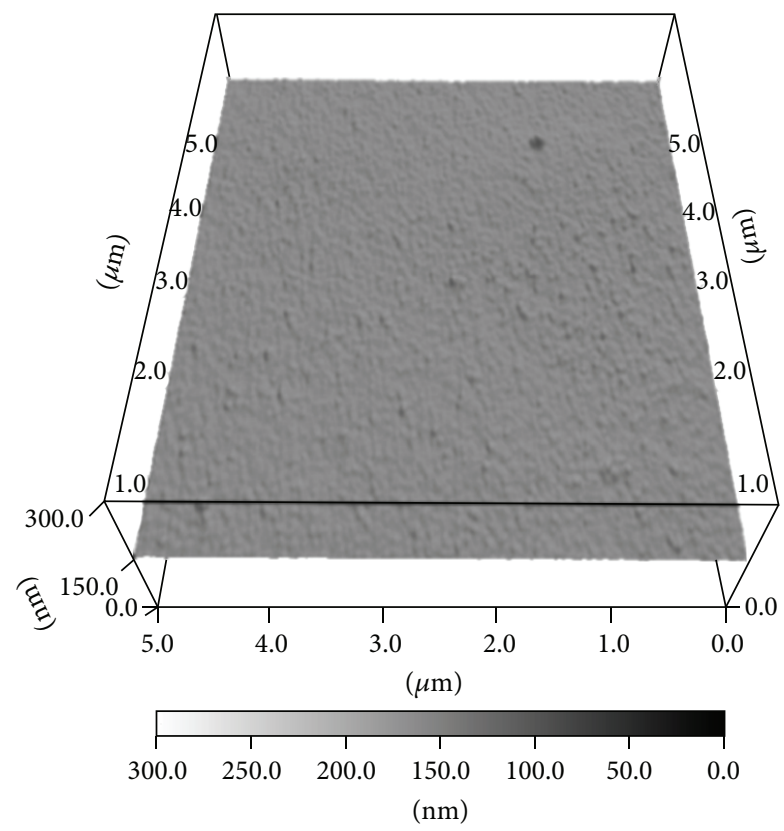

(a)

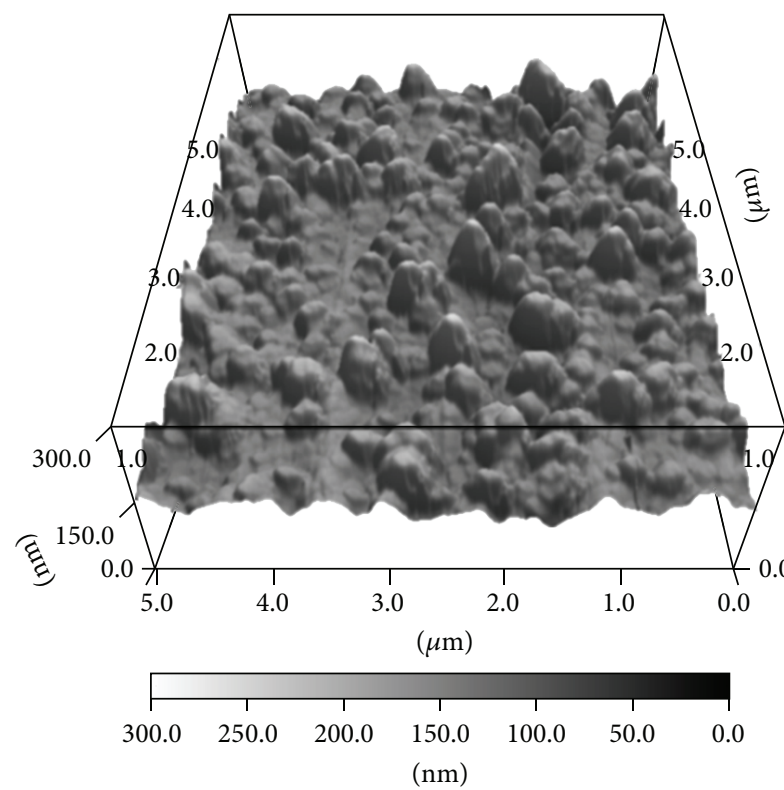

(b)

FIgURE 4: AFM images of Mo-Te thin films as-deposited (a) and (b) annealed at $475^{\circ} \mathrm{C}$ for $15 \mathrm{~min}$ in $\mathrm{N}_{2}$ ambient.
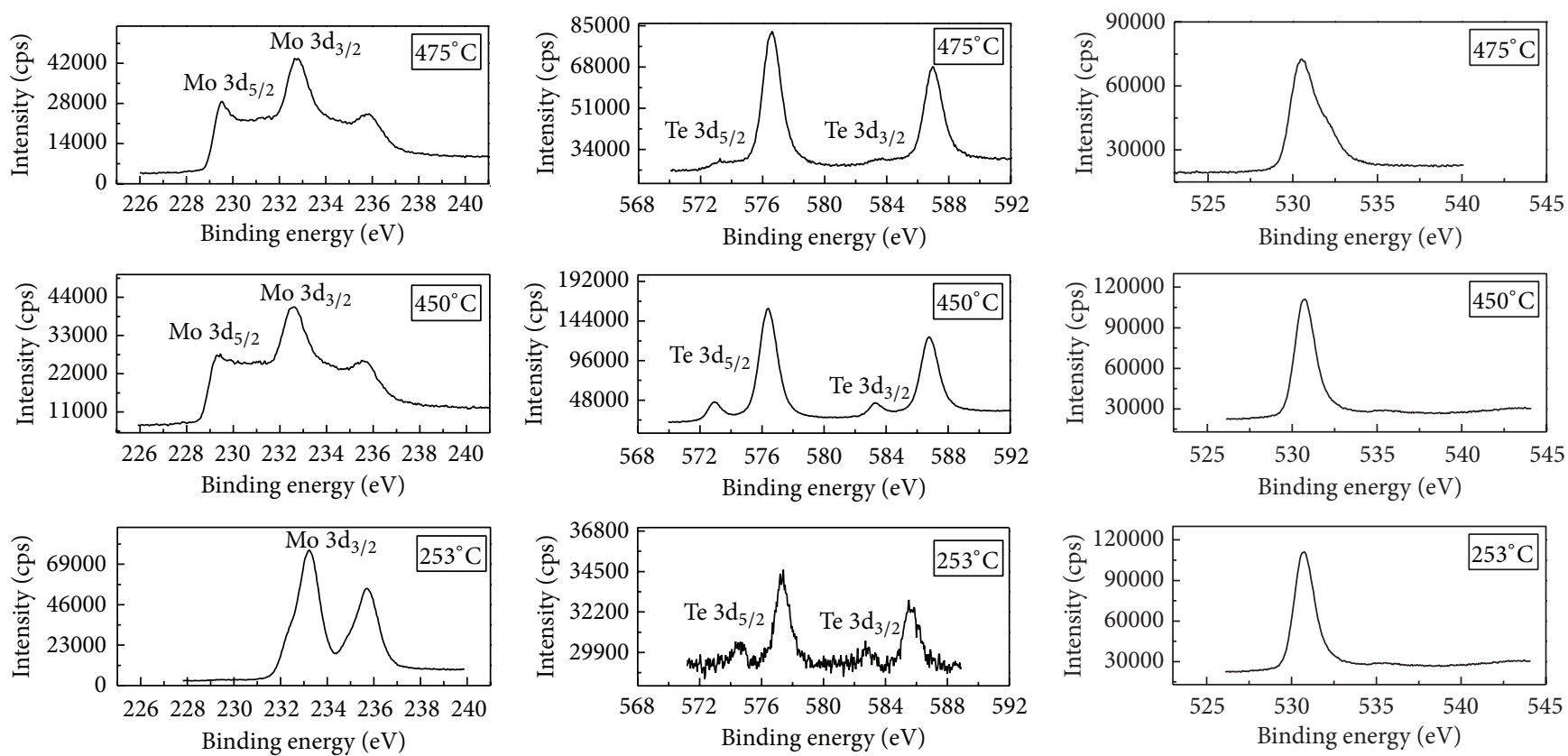

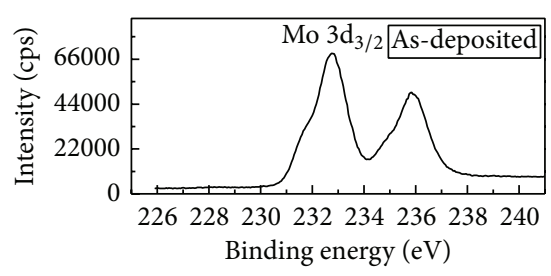

(a)

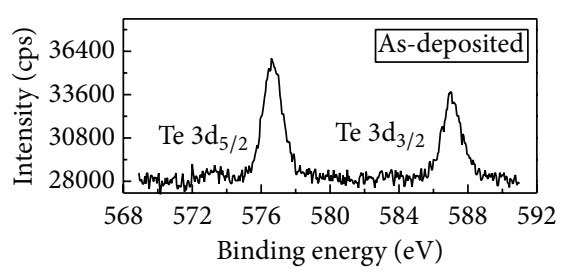

(b)

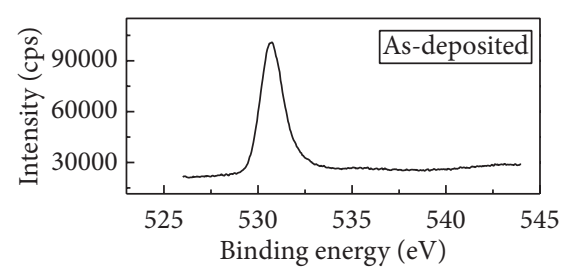

(c)

Figure 5: XPS spectra of (a) Mo 3d, (b) Te 3d, and (c) O 1s for Mo-Te thin films annealed at different temperatures. 


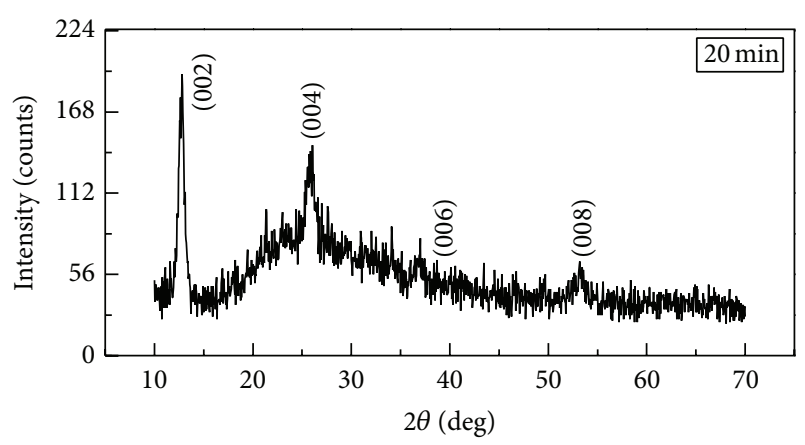

(a)

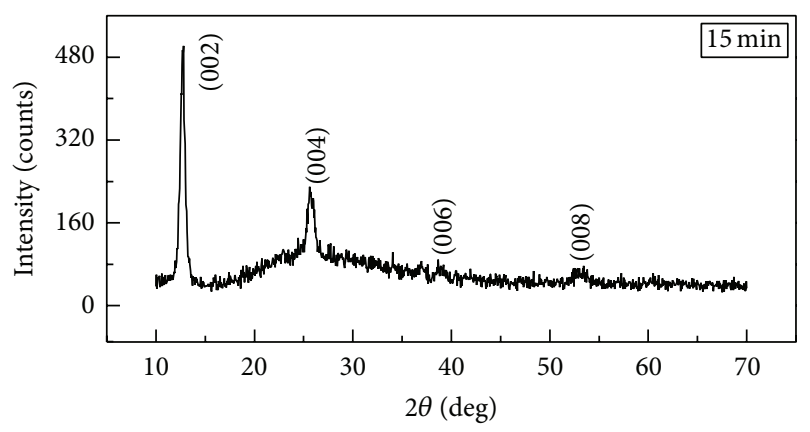

(b)

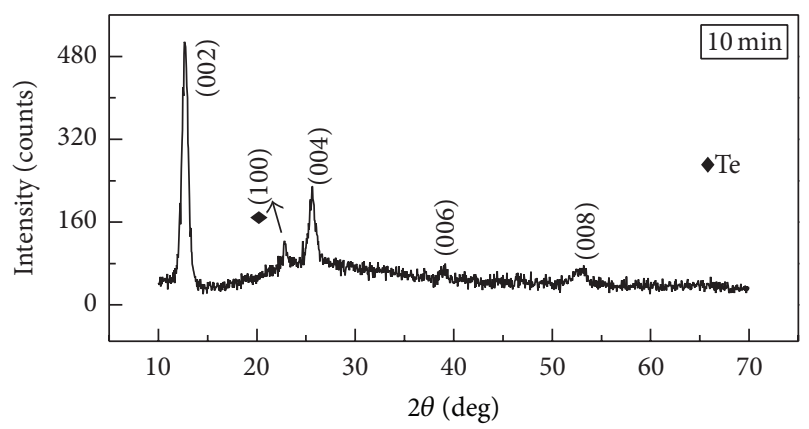

(c)

FIGURE 6: XRD patterns of Mo-Te thin films with thickness of $450 \mathrm{~nm}$ annealed at $470^{\circ} \mathrm{C}$ for different times in $\mathrm{N}_{2}$ ambient.

that a large amount of Te was not alloyed in the as-deposited films. After annealing, most of Te was alloyed with Mo in the form of $\mathrm{MoTe}_{2}$ due to the interdiffusion. This could explain why the peak of Te was firstly detected but disappeared after annealing in XRD patterns (see Figure 1).

To further explore the effect of annealing on the structure of Mo-Te thin films, the other thermal postdeposition treatments such as annealing time and thickness were carried out. Figure 6 shows XRD of Mo-Te thin films with thickness of $450 \mathrm{~nm}$ annealed at $470^{\circ} \mathrm{C}$ for different annealing time. It was noticed that when the annealing time was 10 minutes, peaks of $\mathrm{MoTe}_{2}$ (002), (004), (006), and (008) were revealed with $\mathrm{Te}(100)$ at $23.029^{\circ}$, while the annealing time reached 15 minutes and the Te phase disappeared. With the increase of the annealing time (e.g., 20 minutes), the crystallization of the films was not better than that of the films annealed for 15 minutes and the intensities of the peaks became weak.

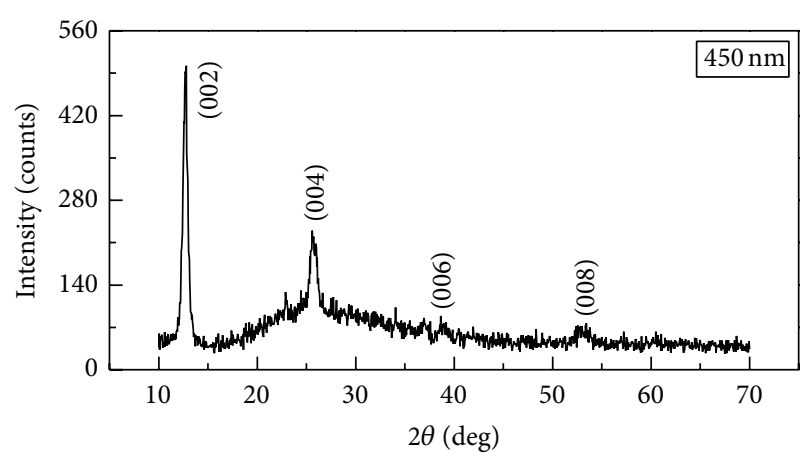

(a)

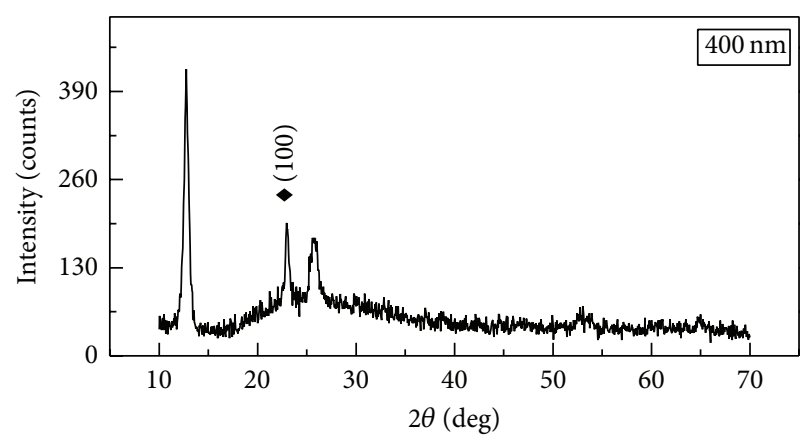

(b)

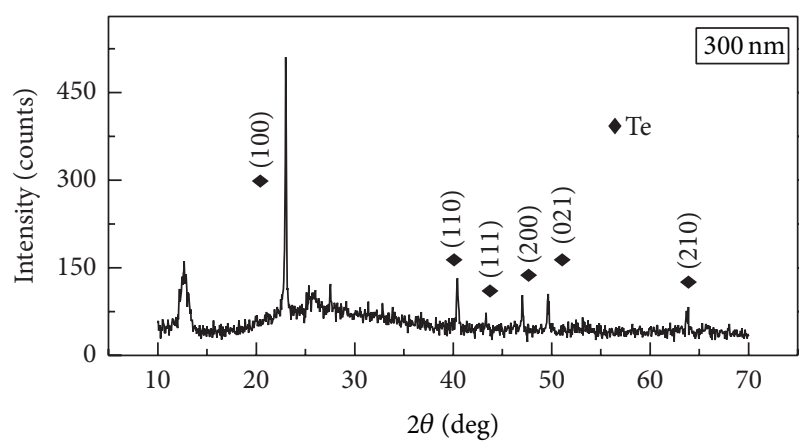

(c)

FIGURE 7: XRD patterns of Mo-Te thin films annealed at $470^{\circ} \mathrm{C}$ in $\mathrm{N}_{2}$ ambient with different thicknesses.

The poor crystallization can be also attributed in part to the reevaporation of tellurium.

From Figure 7, peaks of Te (100), (110), (111), (200), (021), and (210) for $300 \mathrm{~nm}$ thick Mo-Te thin films were detected with $\mathrm{MoTe}_{2}$ (002). As the film thickness increased to $400 \mathrm{~nm}$, the number of diffraction peaks of Te was suppressed and the peak of $\mathrm{MoTe}_{2}$ (004) was firstly observed. With the increase of the thickness for the thin films, more peaks of single phase $\mathrm{MoTe}_{2}$, such as (006) and (008), were detected in the $450 \mathrm{~nm}$ thick Mo-Te thin films.

\section{Conclusions}

Mo-Te thin films were deposited at room temperature by electron beam evaporation, and then the films were annealed in $\mathrm{N}_{2}$ ambient under different conditions. The formation of 
$\mathrm{MoTe}_{2}$ thin films took place at about $350^{\circ} \mathrm{C}$ and the structure of the thin films was stable from room temperature to $500^{\circ} \mathrm{C}$. As the temperature increased, the growth of the $\mathrm{MoTe}_{2}$ phase was predominated and the Te secondary phase was suppressed. The thin films were single phase $\mathrm{MoTe}_{2}$ and well crystallized in the hexagonal structure annealed at $470^{\circ} \mathrm{C}$ or higher. At a temperature of $500^{\circ} \mathrm{C}$ or higher, or even for a long annealing time, the thin films were poor due to the reevaporation of tellurium and the adhesion-loss problems.

\section{Conflict of Interests}

The authors declare that there is no conflict of interests regarding the publication of this paper.

\section{Acknowledgments}

This work was supported by the National Basic Research Program of China (Grant no. 2011CBA007008), National Natural Science Foundation of China (Grant no. 61076058), and the Science and Technology Program of Sichuan Province, China (Grant no. 13ZC2185).

\section{References}

[1] T. Löher, Y. Tomm, C. Pettenkofer, A. Klein, and W. Jaegermann, "Structural dipoles at interfaces between polar II-VI semiconductors CdS and CdTe and non-polar layered transition metal dichalcogenide semiconductors $\mathrm{MoTe}_{2}$ and $\mathrm{WSe}_{2}$," Semiconductor Science and Technology, vol. 15, no. 6, pp. 514-522, 2000.

[2] T. Böker, R. Severin, A. Müller et al., "Band structure of $\mathrm{MoS}_{2}$, $\mathrm{MoSe}_{2}$, and $\alpha-\mathrm{MoTe}_{2}$ : angle-resolved photoelectron spectroscopy and ab initio calculations," Physical Review B: Condensed Matter and Materials Physics, vol. 64, no. 23, Article ID 235305, p. 235305, 2001

[3] A. R. Beal, J. C. Knights, and W. Y. Liang, "Transmission spectra of some transition metal dichalcogenides. II. Group VIA: trigonal prismatic coordination," Journal of Physics C: Solid State Physics, vol. 5, no. 24, pp. 3540-3551, 1972.

[4] Y. Ma, Y. Dai, M. Guo, C. Niu, J. Lu, and B. Huang, "Electronic and magnetic properties of perfect, vacancy-doped, and nonmetal adsorbed $\mathrm{MoSe}_{2}, \mathrm{MoTe}_{2}$ and $\mathrm{WS}_{2}$ monolayers," Physical Chemistry Chemical Physics, vol. 13, no. 34, pp. 15546-15553, 2011.

[5] X. Zong, H. Yan, G. Wu et al., "Enhancement of photocatalytic $\mathrm{H}_{2}$ evolution on CdS by loading $\mathrm{MoS}_{2}$ as cocatalyst under visible light irradiation," The Journal of the American Chemical Society, vol. 130, no. 23, pp. 7176-7177, 2008.

[6] J. A. Wilson and A. D. Yoffe, "The transition metal dichalcogenides discussion and interpretation of the observed optical, electrical and structural properties," Advances in Physics, vol. 18, pp. 193-335, 1969.

[7] J. M. Pawlikowski, "Physical limitations of polycrystalline thin film photoelectric devices," Thin Solid Films, vol. 190, no. 1, pp. 39-64, 1990.

[8] A. Conan, A. Bonnet, A. Amrouche, and M. Spiesser, "Semiconducting properties and band structure of $\mathrm{MoTe}_{2}$ single crystals," Journal de Physique Paris, vol. 45, no. 3, pp. 459-465, 1984.
[9] J. C. Bernede, J. Pouzet, N. Manai, and A. B. Mouais, "Structural characterization of synthesized molybdenum ditelluride thin films," Materials Research Bulletin, vol. 25, no. 1, pp. 31-42, 1990.

[10] A. Ouadah, J. C. Bernede, and J. Pouzet, "MoTe 2 thin films synthesized by solid state reactions between Mo and Te Thin Films," Physica Status Solidi A, vol. 134, no. 2, pp. 455-466, 1992. 

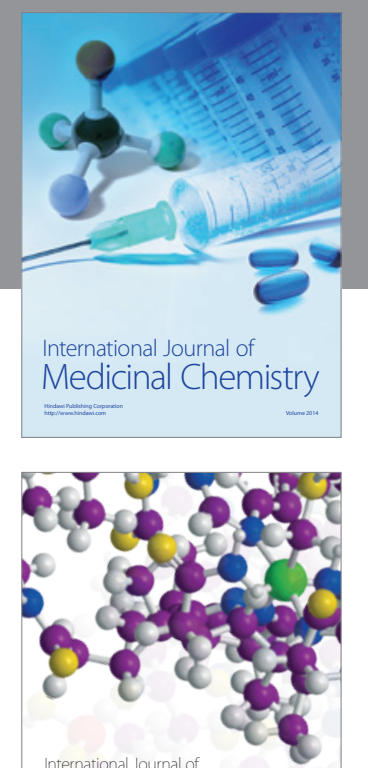

\section{Carbohydrate} Chemistry

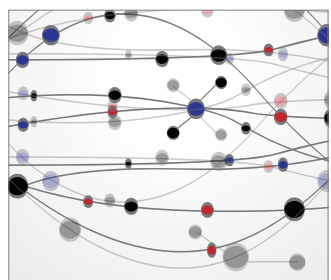

The Scientific World Journal
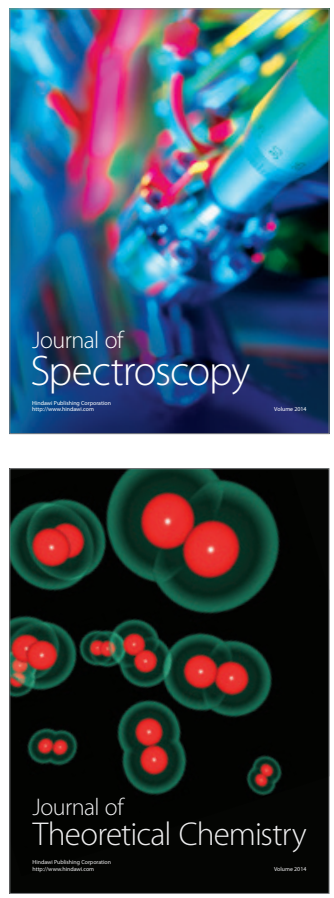
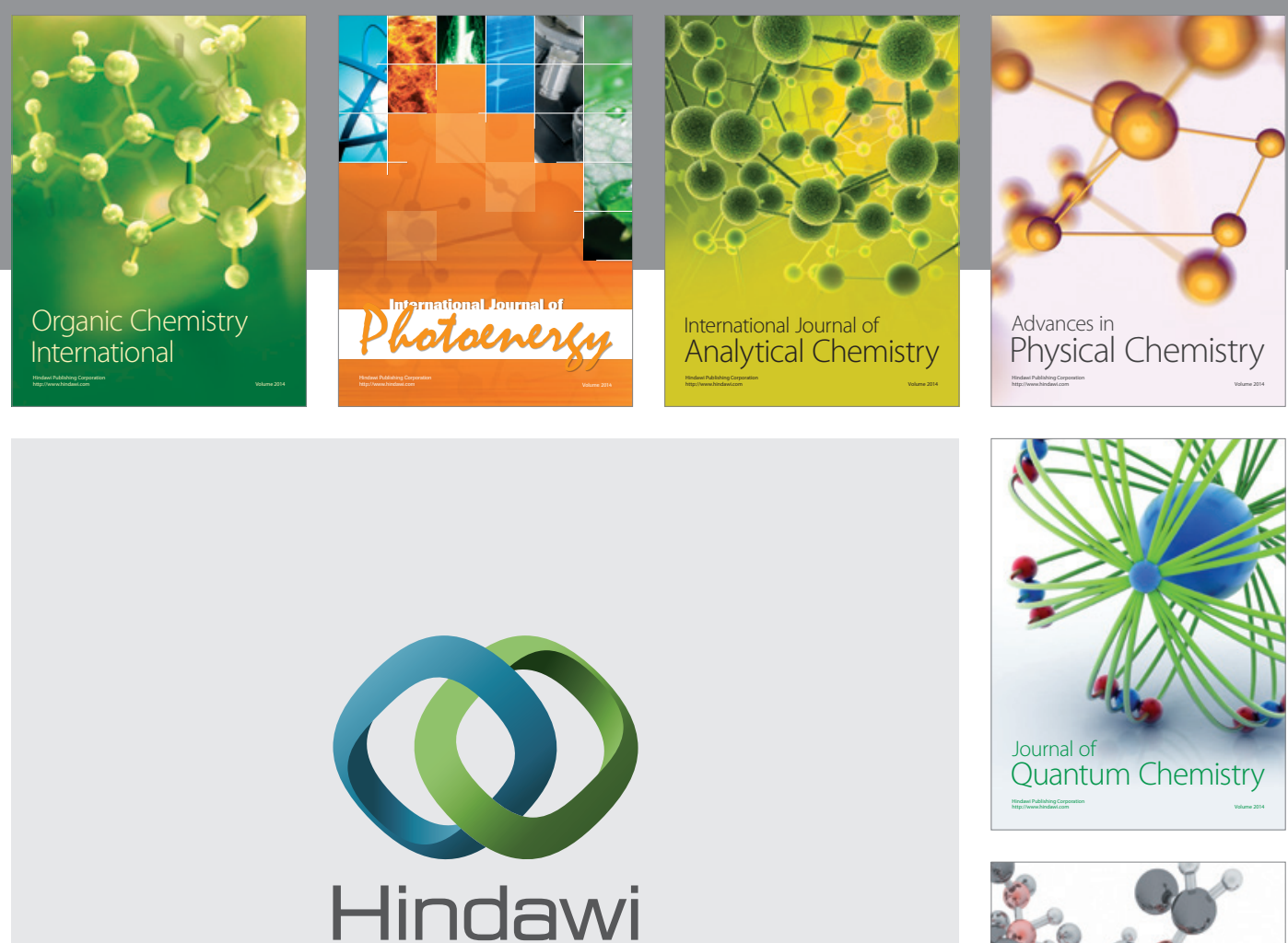

Submit your manuscripts at

http://www.hindawi.com

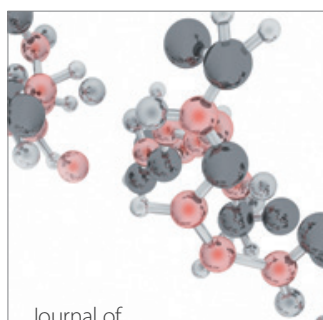

Analytical Methods

in Chemistry

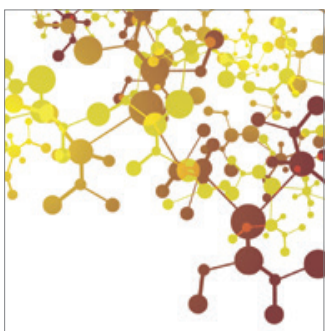

Journal of

Applied Chemistry

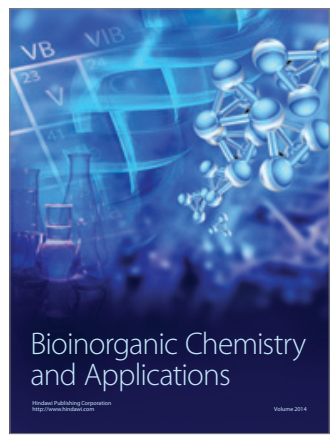

Inorganic Chemistry
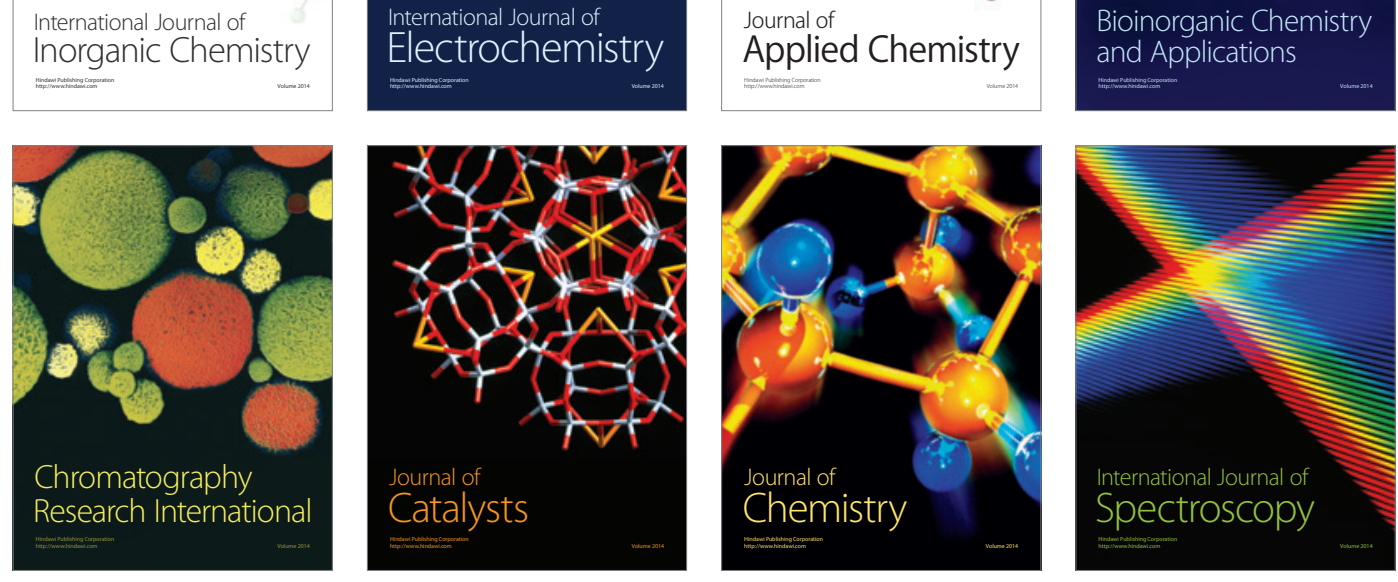